\title{
Diversidad microbiana asociada a la chicha de arroz: una bebida tradicional de Bolívar - Ecuador
}

\section{(Microbial diversity associated to "rice chicha": a traditional beverage in Bolivar - Ecuador)}

\author{
Diana Pazmiño, Micaela Escudero, Nubia Grijalva ${ }^{1}$
}

\begin{abstract}
Resumen:
La provincia de Bolívar se encuentra ubicada en el centro-occidente del Ecuador. Las principales bebidas tradicionales que allí se producen son los aguardientes y las chichas; entre ellas sobresale la chicha de arroz. En una primera etapa, se evaluaron muestras de chicha de arroz (en los puntos de venta) de diferentes productores de la provincia; se realizaron recuentos microbiológicos y análisis físico-químicos. En la segunda etapa, se aislaron e identificaron enterobacterias, bacterias ácido lácticas, mohos y levaduras, en tres fases del proceso de elaboración (inicial, fermentativo y final). Para todos los microorganismos se realizaron descripciones macroscópicas y microscópicas. La identificación de enterobacterias y bacterias ácido lácticas se realizó mediante pruebas bioquímicas, para los mohos se realizó una identificación microscópica mediante tinción con azul de lactofenol y para las levaduras se usó el kit API 20 C AUX. En relación a los recuentos se obtuvieron en promedio valores de 2.7 y $2.5 \mathrm{log} \mathrm{UFC} / \mathrm{ml}$ de coliformes totales y enterobacterias respetivamente, $1.8 \mathrm{log} \mathrm{UFC} / \mathrm{ml}$ de bacterias ácido lácticas y $2.5 \log U \mathrm{UCC} / \mathrm{ml}$ de Mohos y levaduras. Se identificaron en las tres fases: 13 cepas de enterobacterias, 9 cepas de bacterias ácido lácticas, 15 cepas de mohos y 6 cepas de levaduras.
\end{abstract}

Palabras clave: bebidas tradicionales, chicha, fases, microorganismos

\begin{abstract}
:
The province of Bolivar is located in the central-west region of Ecuador. The main beverages produced are spirits and chichas; among them "rice chicha". In a first stage, samples of rice chicha (at points of sale) from different producers of this province were evaluated; microbial counts and physicochemical analyzes were performed. In the second stage, the most representative enterobacteria, lactic acid bacteria, yeasts and molds were isolated form "rice chicha" during three phases of the elaboration process: initial, fermentative and final. For all microorganisms, macroscopic and microscopic descriptions were performed. The identification of enterobacteria and lactic acid bacteria was carried out with biochemical tests, for mold a microscopic identification was applied by staining with lactophenol blue solution and for yeast the APIC AUX 20 kit was used. Count values in average were 2.7 and $2.5 \mathrm{log}$ CFU / $\mathrm{ml}$ of total coliforms and enterobacteria, $1.8 \mathrm{log}$ CFU / $\mathrm{ml}$ of lactic acid bacteria and $2.5 \mathrm{log}$ CFU / $\mathrm{ml}$ for yeasts and molds. During the three fermentation phases the most representative species were partially identified: 13 strains of Enterobacteriaceae, 9 strains of lactic acid bacteria, 15 strains of mold and 6 strains of yeast.
\end{abstract}

Keywords: traditional beverage, chicha, stages, microorganisms

\footnotetext{
${ }^{1}$ Universidad Tecnológica Equinoccial, Quito - Ecuador (gvnj87974@ute.edu.ec)
} 


\section{Introducción}

La producción de arroz en el Ecuador tiene sus inicios en el siglo XVIII, pero se fortaleció su consumo y comercialización en el siglo XIX. Este cultivo se desarrolló en un principio en las provincias del Guayas, Manabí, y Esmeraldas, y con el tiempo logró extenderse y comercializarse en la región Sierra. El arroz es el cultivo más extenso del Ecuador; ocupa más de la tercera parte de la superficie de productos transitorios del país. En el año 2009 la producción de este cereal en el país alcanzó 1'579406 toneladas anuales (INEC, 2009).

El Ecuador es un país con una gran diversidad cultural y étnica, lo que implica costumbres y tradiciones diversas, las mismas que han sido transmitidas de generación en generación. Una de ellas es la elaboración de la bebida ancestral considerada sagrada desde tiempos pasados denominada "chicha", bebida fermentada no destilada elaborada a base de cereales originarios de América (Aguirre, 2009). Las chichas en el Ecuador son elaboradas a partir de distintos sustratos como el maíz, arroz, quinua, avena, harina de jora, yuca, entre otros, acompañadas de frutas de la zona como naranjilla, piña, mora, tomate de árbol, taxo, entre otras; se las endulza con azúcar, jugo de caña o panela y se las deja fermentar en pondos de barro o recipientes de plástico de 3 hasta 20 días, dependiendo del grado de concentración alcohólica que se desee (Bayas, Jines, Salazar, \& Del Pozo, sf; Ministerio de Turismo del Ecuador, 2012).

La preparación de esta bebida representa un gran componente cultural principalmente a nivel de las comunidades indígenas sobretodo en sus fiestas y celebraciones. Además, su aceptación ha aumentado notablemente en la población mestiza, se consume con frecuencia en la Serranía y Amazonía, sin embargo también se lo hace en menor cantidad en la Costa. En la provincia de Bolívar, la "chicha" es la bebida oficial del Carnaval (fiesta mayor de la provincia), en esta fecha las familias bolivarenses preparan esta bebida con los mejores ingredientes en un "pondo de barro" y es ofrecida a los turistas (Rosas, 2012; López, Ramírez, Mambuscay, \& Osorio, 2010).

La "Chicha de Arroz" es una bebida de sabor dulce y suave, considerada como una bebida histórica que puede constituirse desde refresco hasta una especie de vino embriagante (Proaño, 2009). Es una bebida ancestral elaborada con su principal ingrediente, el arroz. Su preparación presenta varias modificaciones de acuerdo a la zona, pero fundamentalmente consiste en moler el grano, remojarlo, cocinarlo, añadir agua y endulzarlo, también se añade especias como: canela, clavo de olor, congona (planta de jardín), hierba luisa; además de eso se suele adicionar frutas como la piña, naranjilla o guayaba para posteriormente filtrar la mezcla; se sirve fresca o fermentada (Ramírez, Rosas, Velázquez, Ulloa, \& Arce, 2011; Proaño, 2009). Esta bebida es elaborada de forma tradicional, con la aplicación de recetas que han sido modificadas con el pasar del tiempo. La etapa de fermentación tarda de 4 a 15 días, según los ingredientes usados (López, Ramírez, Mambuscay, \& Osorio, 2010). 
Los sustratos que atraviesan por un proceso de fermentación espontáneo (sin adición de un inóculo específico), representan hábitats de gran importancia para el estudio de microorganismos nativos (López, Ramírez, Mambuscay, \& Osorio, 2010). En las bebidas fermentadas la microbiología es muy variada, debido a la naturaleza del sustrato, los agentes selectivos existentes en el medio, el pH bajo y la gran concentración de $\mathrm{CO}_{2}$. Generalmente, en este tipo de bebidas se han detectado una mezcla de microorganismos responsables de la fermentación e indicadores de la calidad microbiológica como bacterias, mohos y levaduras (Decheco , 2009; Fula, 2010).

Los consorcios microbianos (asociaciones naturales de dos o más poblaciones microbianas) que son frecuentemente encontrados en varias bebidas fermentadas dan lugar a interacciones positivas que favorecen a todas las poblaciones presentes en relación a la captación de nutrientes, eliminación de ciertos metabolitos que llegan a ser tóxicos si se acumulan en la bebida y control de la flora microbiana alterante de la fermentación (Cervantes \& Pedroza, 2007).

Es importante conocer la microbiología presente en estas bebidas debido a que son el producto de la actividad de varios grupos de microorganismos. La presencia de microorganismos indicadores como enterobacterias y coliformes totales podría señalar una contaminación en materias primas, equipos y utensilios sucios o manejo no higiénico, el desarrollo de microorganismos denominados fermentadores (bacterias ácido lácticas, mohos y levaduras), los cuales se encuentran de forma natural y son los responsables de que se produzca la fermentación, además de que le otorgan a las bebidas nuevas características físico-químicas y sensoriales particulares o propias(Comisión Internacional de Especificaciones Microbiológicas para Alimentos, 2000; (Gamazo, López, \& Díaz, 2009).

La escasa información disponible sobre bebidas fermentadas tradicionales que se producen y comercializan en la provincia de Bolívar fue la razón más importante por la cual se llevó a cabo esta investigación. Fue necesario realizar estudios para determinar la calidad de las bebidas fermentadas tradicionales más representativas de esta provincia en base a parámetros físicoquímicos y microbiológicos para conocer el estado en el que se producen y comercializan, con la finalidad de determinar qué tan aptas son para el consumo en relación al cumplimiento de normas o en comparación con estudios similares. Además el identificar la diversidad microbiana presente en la chicha de arroz de la Provincia de Bolívar. Los objetivos específicos fueron: obtener muestras de chichas de arroz de la Provincia Bolívar, realizar análisis microbiológicos a la muestras y determinar qué tipos de microorganismos (enterobacterias, bacterias ácido lácticas, mohos y levaduras) se encuentran presentes en la chicha de arroz. 


\section{Metodología}

\subsection{Material}

Se analizaron muestras de chicha de arroz de la provincia Bolívar de dos productores diferentes, de tres lotes de producción. Para la evaluación de la calidad microbiológica de la bebida las muestras fueron tomadas en la etapa de elaboración en botellas de vidrio herméticas previamente etiquetadas y esterilizadas; fueron transportadas en condiciones de refrigeración.

Para el aislamiento e identificación de los microorganismos las muestras fueron tomadas una vez elaboradas las bebidas en botellas de vidrio herméticas previamente etiquetadas y esterilizadas, se dejaron fermentar espontáneamente durante 15 días a temperatura ambiente.

\subsection{Recuentos microbiológicos}

Se realizaron diluciones sucesivas según la norma técnica ecuatoriana INEN 1529-2 (1999). Para la inoculación de las placas se utilizaron 3 diluciones sucesivas por cada muestra, se aplicó la técnica de siembra por profundidad. Se colocó $1 \mathrm{ml}$ de cada dilución en las placas y se añadió $20 \mathrm{ml}$ del medio de cultivo fundido y atemperado a $45-50^{\circ} \mathrm{C}$. Las especificaciones de medios y condiciones de siembra se detallan en la Tabla 1.

Tabla 1. Medios de cultivo selectivos usados para el recuento y aislamiento de cepas.

\begin{tabular}{|l|l|l|}
\hline Microorganismo & Medio de cultivo & $\begin{array}{l}\text { Condiciones } \\
\text { incubación }\end{array}$ \\
\hline Enterobacterias & Agar MacConkey & $35^{\circ} \mathrm{C} ; 18$ a 24 horas. \\
\hline Coliformes & Agar VRB & $35^{\circ} \mathrm{C} ; 18$ a 24 horas. \\
\hline Mohos y Levaduras & $\begin{array}{l}\text { Agar PDA + 40 ppm de } \\
\text { gentamicina }\end{array}$ & $25^{\circ} \mathrm{C} ; 3$ - 5 días \\
\hline Aerobios mesófilos & Agar PCA & $35^{\circ} \mathrm{C} ; 18$ a 24 horas \\
\hline Bacterias ácido lácticas & Agar MRS & $\begin{array}{l}\text { Cámara de anaerobiosis; } \\
37^{\circ} \mathrm{C} ; 24 \text { a 48 horas. }\end{array}$ \\
\hline
\end{tabular}

Se utilizó esta misma técnica en cada una de las tres fases del proceso de elaboración (inicial, fermentativo y final) para realizar un recuento aproximado de las poblaciones y aislar cepas de acuerdo a características macroscópicas y microscópicas

\subsection{Análisis físico - químicos}

Las muestras fueron llevadas bajo condiciones de refrigeración al laboratorio. Se realizaron los siguientes análisis: grado alcohólico, metanol, ésteres, aldehídos, peso específico, extracto seco, acidez total y fija. Se siguió la normativa establecida por las normas INEN (340, 347, 342, 343, $346,341)$. 


\subsection{Aislamiento e identificación}

Los aislamientos fueron realizados con la técnica por estría hasta obtener cultivos puros, tomando en cuenta criterios morfológicos y fenotípicos de los microorganismos de interés; en el caso de los mohos se aplicó la técnica de depósito.

Se realizó tinción Gram a los microorganismos, para poder determinar si los microorganismos eran Gram positivos ó Gram negativos, a excepción de los mohos.

La identificación de enterobacterias y bacterias ácido lácticas se realizó por medio de pruebas bioquímicas; para las enterobacterias se realizó 11 tipos de pruebas, entre estas: uso de carbohidratos, producción de indol, formación de ácidos, uso del citrato, producción de sulfuro, movilidad, catalasa, hidrólisis de la urea, producción de lisina descarboxilasa, resistencia a la sal y uso de manitol; para las bacterias ácido lácticas se realizó 6 tipos de pruebas, entre estas: catalasa, aerobiosis, anaerobiosis, producción de indol, producción de sulfuro, movilidad; una vez obtenidos los resultados fueron comparados con el Bergey's Manual of Determinative Bacteriology (Holt , Krieg, Sneath, Staley, \& Williams, 1994). En el caso de los mohos se aplicó la técnica de visualización por tinción con azul de lactofenol, una vez obtenidos los resultados se comparó con el Manual Introduction to Food-Borne Fungi (Samson, Hoekstra, Frisvad, \& Filtenborg, 1995) . Las levaduras fueron identificadas con el uso del kit de identificación API 20 C AUX (BIOMERIUX, 2010)

\section{Resultados y Discusión}

\subsection{Calidad microbiológica de las bebidas}

No se obtuvieron diferencias significativas entre productores para la mayoría de los indicadores microbianos evaluados a excepción de las bacterias ácido-lácticas, esto podría atribuirse a tiempos distintos de fermentación. Los valores promedios obtenidos se presentan en la tabla 2.

En cuanto a los microorganismos fermentadores en el estudio del perfil microbiológico de la chicha de arroz de Venezuela, realizado por Arroyo, Bencomo, \& Bianco (2011) reportaron como valor máximo permitido 3 log UFC/ml de mohos y levaduras. Para bacterias ácido lácticas Gassem (2002), reportó en un estudio realizado en una bebida de trigo y malta denominada Sobia, originaria de Arabia Saudita, valores de 4.10 a 8.19 log UFC/ml. La chicha de arroz evaluada en este estudio posee recuentos bajos de microorganismos fermentadores lo cual podría atribuirse al periodo corto de fermentación (3-5 días).

En relación a los microorganismos indicadores, en un estudio acerca de la contaminación enterobacteriana del guarapo de uva realizado por Cartagena, Centellas, Torrico, Saavedra, \& Sejas, (2009), se discute que los valores de recuento son elevados si sobrepasan las 2.70 log $\mathrm{UFC} / \mathrm{ml}$ relacionadas directamente con patologías generalmente gastrointestinales. Para 
coliformes totales en el estudio microbiológico realizado por Gassem (2002) se obtuvieron valores entre 0,67 y 3,84 log UFC/ml. De acuerdo a estos parámetros se deduce que la chicha de arroz presenta recuentos cercanos al límite permitido, comparados con los obtenidos en otros estudios en cuanto a microorganismos indicadores.

Tabla 2. Recuentos microbianos obtenidos en chichas de arroz en condiciones de expendio (2 productores distintos, 3 lotes de producción)

\begin{tabular}{|c|c|c|}
\hline \multirow[t]{2}{*}{ Microorganismo } & Productor 1 & Productor 2 \\
\hline & \multicolumn{2}{|c|}{ Log UFC/ml } \\
\hline \multirow[t]{2}{*}{ Mohos y levaduras } & $2.36 \pm 0.52$ & $2.60 \pm 0.48$ \\
\hline & \multicolumn{2}{|c|}{ Tukey $_{\text {productor }}=0.644$} \\
\hline \multirow[t]{2}{*}{ Coliformes } & $2.41 \pm 0.42$ & $2.55 \pm 0.53$ \\
\hline & \multicolumn{2}{|c|}{ Tukey $_{\text {productor }}=0.610$} \\
\hline \multirow[t]{2}{*}{ Enterobacterias } & $2.27 \pm 0.43$ & $2.59 \pm 0.50$ \\
\hline & \multicolumn{2}{|c|}{ Tukey $_{\text {productor }}=0.602$} \\
\hline \multirow[t]{2}{*}{ Ácido lácticas } & $1.32 \pm 0.32$ & $1.84 \pm 0.3$ \\
\hline & \multicolumn{2}{|c|}{ Tukey $_{\text {productor }}=0.402$} \\
\hline \multirow[t]{2}{*}{ Aerobios mesófilos } & $2.57 \pm 0.54$ & $3.08 \pm 0.38$ \\
\hline & \multicolumn{2}{|c|}{ Tukey $_{\text {productor }}=0.602$} \\
\hline
\end{tabular}

\subsection{Caracterización físico-química}

La bebida analizada tuvo en promedio $0.24^{\circ} \mathrm{GL}$ de alcohol lo que indica un tiempo de fermentación corto. El pH promedio fue de 4.02 y la acidez total fue de 33700 mg de ácido acético / $100 \mathrm{ml}$ de alcohol anhidro; el aumento de la acidez podría atribuirse a las actividades de las bacterias ácido lácticas que descomponen los azúcares para transformarlos en ácido láctico.

El contenido de aldehídos fue de $71.29 \mathrm{mg}$ de etanal/ $100 \mathrm{ml}$ alcohol anhidro y de ésteres fue de $1447.8 \mathrm{mg}$ acetato de etilo/100ml alcohol anhidro. Estela et al., (2011) manifiestan que los ésteres representan el mayor grupo de componentes aromáticos, por lo que un alto contenido podría contribuir a las características organolépticas del producto. No se detectaron niveles de metanol en ninguna de las muestras evaluadas.

\subsection{Identificación de microorganismos en chicha de arroz}

Los microorganismos aislados en la chicha de arroz representaron un consorcio de enterobacterias, bacterias ácido lácticas (Tabla 3), mohos y levaduras (Tabla 4). Los valores de los recuentos fueron diferentes en las tres fases del proceso de elaboración. Según Sanchez et al., (2010), en una bebida fermentada se recrea un ecosistema con una amplia diversidad microbiana, las relaciones entre los microorganismos desarrollados en ella y su metabolismo 
ejercen una influencia en las propiedades organolépticas de la bebida, así como en su duración y mejoramiento de su calidad nutritiva.

Tabla 3. Identificación inicial de bacterias en chicha de arroz de acuerdo a: características macroscópicas, microscópicas y fisiológicas.

\begin{tabular}{|l|l|c|}
\hline \multicolumn{1}{|c|}{ Tipo } & \multicolumn{1}{|c|}{ Especies identificadas } & Etapa de aislamiento \\
\hline \multirow{4}{*}{ Enterobacterias } & Providencia stuartii & 1 \\
\cline { 2 - 3 } & Edwarsiella hoshinae & 1,3 \\
\cline { 2 - 3 } & Buttiauxella agrestis & 1,3 \\
\cline { 2 - 3 } & Obesum bacterium proteus & 1 \\
\cline { 2 - 3 } & Escherichia coli & 1 \\
\cline { 2 - 3 } & Serratia fonticola & 1 \\
\cline { 2 - 3 } & Proteus penneri & 1 \\
\cline { 2 - 3 } & Yersinia rohdei & 1 \\
\cline { 2 - 3 } & Yokonella s.p. & 1 \\
\cline { 2 - 3 } & Erwinia persicinus & 1 \\
\cline { 2 - 3 } & Klebsiella oxytoca & 1 \\
\cline { 2 - 3 } & Enterobacter aerogenes & 1 \\
\cline { 2 - 3 } & Yersinia aldovae & 2,3 \\
\hline \multirow{4}{*}{ Ácido lácticas } & Bacillus (2) & 2.3 \\
\cline { 2 - 3 } & Lactobacillus (5) & 1,2 \\
\cline { 2 - 3 } & Sporolactobacillus (2) & 1 \\
\hline
\end{tabular}

Las muestras de chicha de arroz indicaron altos contenidos de enterobacterias en la etapa inicial del proceso fermentativo, mientras que no se encontró la presencia de ellas en la etapa fermentativa; según Jiménez, González, Magaña, \& Corona (2010), las bacterias patógenas reaccionan de maneras diferentes ante la presencia de bacterias ácido lácticas, lo que hace difícil que dichos microorganismos puedan sobrevivir, haciendo a los alimentos fermentados más seguros para su consumo. En la etapa final se detectó una pequeña cantidad de enterobacterias posiblemente por una recolonización por condiciones ambientales.

La cantidad de bacterias ácido lácticas encontradas fue considerable en las 3 etapas fermentativas notándose una pequeña diferencia en la segunda etapa del proceso en donde el recuento fue mayor; en una investigación realizada por Giles et al., (2001) con Pulque, bebida de origen mexicano, se reportaron recuentos superiores $8,50 \log \mathrm{UFC} / \mathrm{ml}$ de bacterias ácido lácticas en la etapa de fermentación, y en la etapa de finalización del proceso fermentativo se encontró $8,17 \log$ UFC/ml. En el trabajo realizado por Sánchez et al. (2010), el Axokot una bebida fermentada tradicional de origen mexicano presentó 2,91 log UFC/ml de bacterias ácido lácticas en la etapa de fermentación, lo que indica que la cantidad de bacterias ácido lácticas depende de la etapa de fermentación que atravieza el sustrato, las condiciones de fermentación, además de los ingredientes y los utensilios utilizados en la elaboración. 
Tabla 4. Identificación inicial de hongos en chicha de arroz de acuerdo a: características macroscópicas, microscópicas y fisiológicas.

\begin{tabular}{|c|c|c|}
\hline Tipo & Especies identificadas & Etapa de aislamiento \\
\hline \multirow[t]{15}{*}{ Mohos } & Absidia corymbifera & 1 \\
\hline & Aspergillus penicillioides & 1 \\
\hline & Penicillum funicolosum & 1 \\
\hline & Emericella nidulans & 2 \\
\hline & Aspergillus flavus & 2 \\
\hline & Fusarium semitectum & 2 \\
\hline & Penicillium glabrum & 1,2 \\
\hline & Penicillium brevicompactum & 2,3 \\
\hline & Penicillium italicum & 2 \\
\hline & Fusarium solani & 2 \\
\hline & Penicillium funicolosum & 2 \\
\hline & Aspergillus versicolor & 2 \\
\hline & Aspergillus flavus & 1 \\
\hline & Emericella nidulans & 1 \\
\hline & Aspergillus ustus & 3 \\
\hline \multirow[t]{6}{*}{ Levaduras } & Rhodotorula mucilaginosa & $1,2,3$ \\
\hline & Saccharomyces cerevisiae & 1,2 \\
\hline & Candida guilliermondii & 1 \\
\hline & Candida sphaerica & 2 \\
\hline & Trichosporon mucoides & 3 \\
\hline & Candida utilis & 3 \\
\hline
\end{tabular}

En relación a la cantidad de mohos presentes en las muestras de chicha; en la etapa 1 y 2 del proceso fermentativo no variaron considerablemente dichos valores, sin embargo en la tercera etapa del proceso no se encontraron niveles detectables de los mismos. Los resultados de la presente investigación representan cantidades elevadas comparadas con el estudio microbiológico realizado en chicha de arroz de venta ambulante en Venezuela donde se reportó un total de 2,93 log UFC/ml (Arroyo, Bencomo \& Bianco, 2011).

Los recuentos en relación a las levaduras durante las 3 etapas no difirió en forma considerable entre etapas, son cantidades elevadas comparadas con el estudio microbiológico realizado en chicha de arroz de venta ambulante en Venezuela donde se reportó un total de 3,16 log UFC/ml (Arroyo, Bencomo \& Bianco, 2011); así como también la cantidad reportada casi no difiere en forma notable de acuerdo a un estudio microbiológico realizado con pulque ya que se reportó un valor de 5,78 log UFC/ml (Cervantes \& Pedroza, 2007).

La mayor parte de enterobacterias encontradas, fueron de los géneros: Escherichia, Enterobacter, Klebsiella y Proteus, Erwinia, (Figura 1) las mismos que pueden desarrollarse en hábitats diversos como suelo, aguas residuales, agua de río, agua natural, agua contaminada, heces fecales, en 
ocasiones pueden encontrarse en la piel y en la mucosa de las personas o estar presente en algunos tipos de alimentos como frutas, vegetales y alimentos fermentados; lo que sugiere que dicha contaminación podría deberse a errores en la higiene y manipulación de los ingredientes durante la elaboración (Holt , Krieg, Sneath , Staley, \& Williams, 1994; Dworkin, Falkow, Rosenberg, Schleifer, \& Stackebrandt, 2006; Grimont \& Grimont, 2006; Bagley, 1985;; Noriha, Hamidun, \& Indu, 2011).

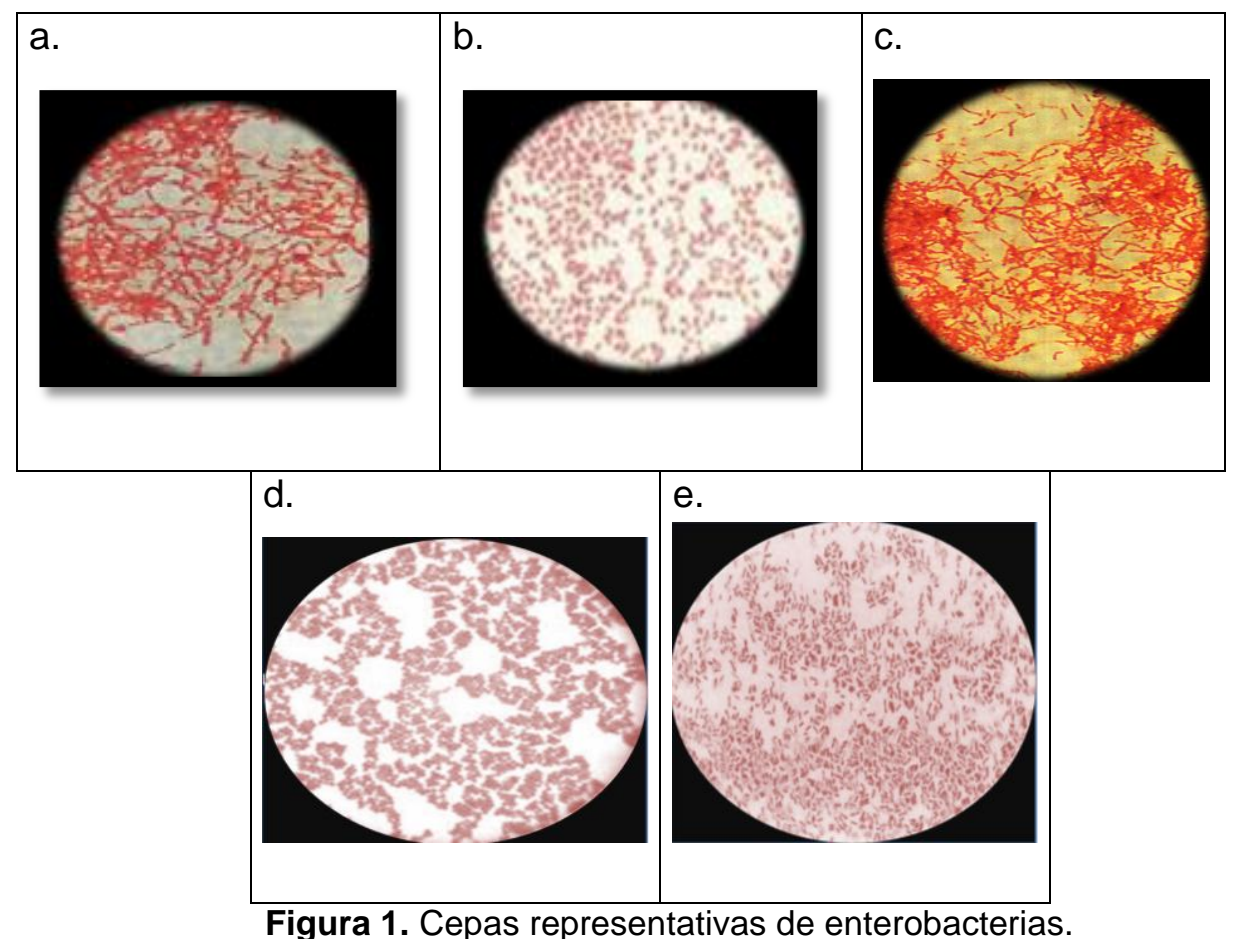

a. Escherichia; b. Erwinia; c. Klebsiella; d. Proteus; e. Enterobacter.

Se obtuvieron 9 cepas distintas de bacterias ácido lácticas, pertenecientes a los géneros: Lactobacillus, Sporolactobacillus y Bacillus (Figura 2). Sporolactobacillus es un tipo de bacteria ácido láctica que tiene como hábitat productos fermentados y salmueras; se ha comprobado que también se desarrollan en las heces de los animales herbívoros, aguas residuales, por lo que indica su posible asociación con alimentos. La presencia de estas bacterias podría atribuirse a la falta de precaución en la elaboración de la bebida (Sanders, Morelli, \& Tompkins, 2003; Stainer, Ingraham, Wheelis, \& Painter, 2005; García, Arrázola, \& Durango, 2010). Bacillus es considerada una bacteria ubicua por su distribución, comúnmente se encuentra en el suelo, agua, polvo y aire; en los alimentos como harinas, cereales, frutas, vegetales; en ocasiones puede desempeñar un papel en el deterioro de los alimentos; además tiene un gran uso en la industria alimenticia, en especial en los lácteos; lo que sugiere que esta especie podría deberse a los ingredientes utilizados y al proceso de fermentación que cruza (Sanders, Morelli, \& Tompkins, 2003; Stainer, Ingraham, Wheelis, \& Painter, 2005). 


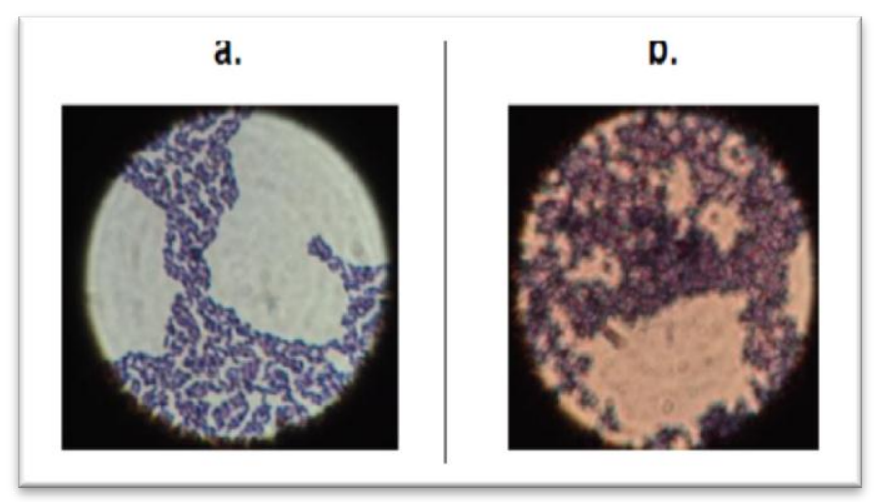

Figura 2. Cepas representativas de bacterias ácido lácticas.
a. Bacillus;
b. Sporolactobacillus

Los principales mohos encontrados pertenecieron a los géneros Aspergillus, Penicillum $y$ Fusarium (Figura 3), los mismos que son considerados ubicuos por su distribución mundial, principalmente están asociados con la tierra, aire, cereales, vegetales y frutas en descomposición; pueden estar asociados a los ingredientes y por ende a la forma de elaboración de la bebida (Reiss, Shadomy, \& Lyon, 2012; Samson, Hoekstra, Frisvad, \& Filtenborg, 1995).

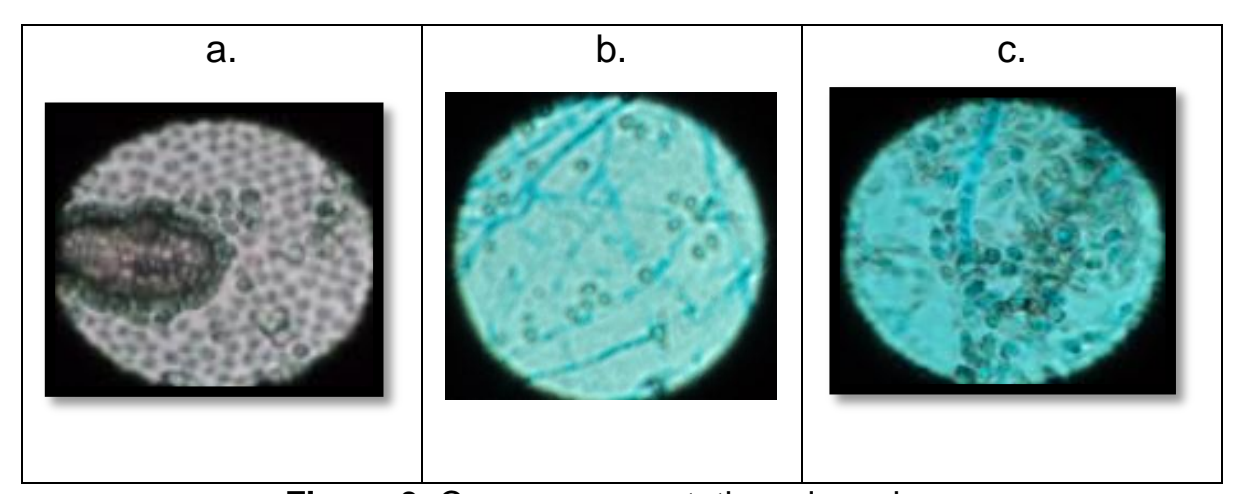

Figura 3. Cepas representativas de mohos.

a. Aspergillus; b. Penicillium; c. Fusarium.

En relación a las levaduras identificadas la mayoría de ellas son comunes en productos fermentados y se asocian a los ingredientes y forma de preparación de la bebida (Figura 4). Rhodotorula mucilaginosa que se caracteriza por la coloración rojo salmón de sus colonias, se considera ubicua debido a su distribución mundial en el agua, suelo, agua dulce y hábitats marinos. Posee una gran capacidad de colonizar una gran variedad de sustratos (Libkind, Gadanho, \& Broock, 2007).

Saccharomyces cerevisiae, considerada como una especie modelo para estudios biológicos y genómicos, se encuentra sobre sustratos ricos en azúcares o en los exudados y savias dulces de algunas plantas. Es muy importante por su funcionalidad en la industria alcohólica, panadera, cervecera; además de que forma compuestos aromáticos, mejora del valor nutritivo de los alimentos, posee efectos probióticos, inhibición de microorganismos no deseados (Jerpersen, 2002). 


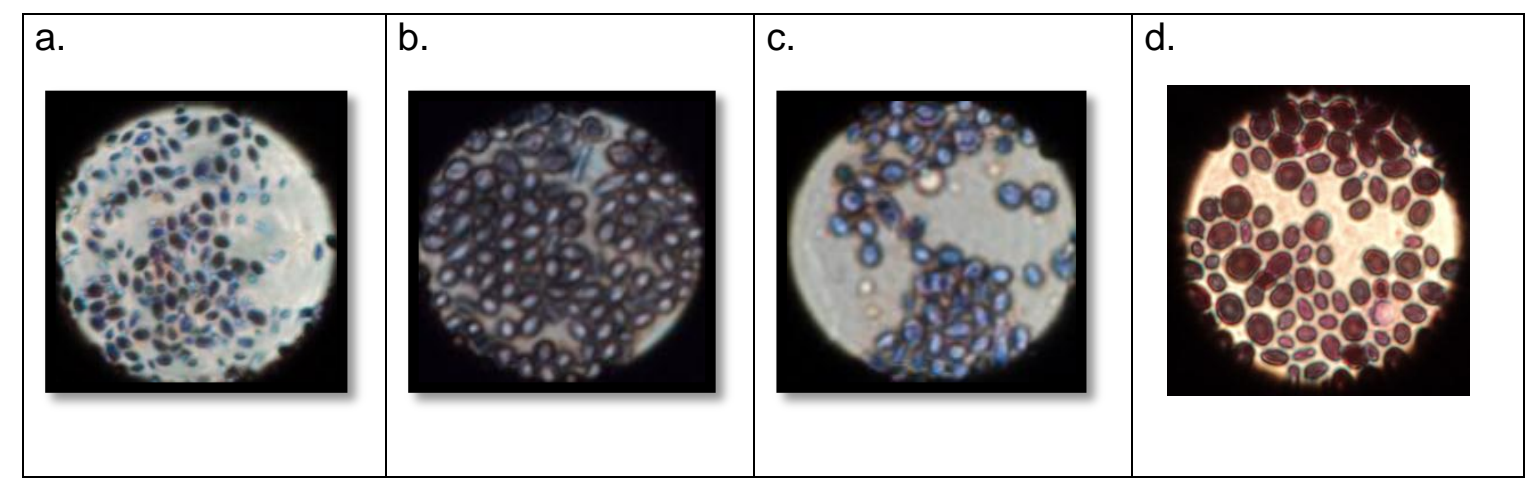

Figura 4. Cepas representativas de Levaduras.

a. Candida; b. Rhodotorula; c. Saccharomyces; d. Trichosporon.

Trichosporon mucoides, tiene como hábitat natural el suelo, agua de río, agua de mar, agua de lagos, plantas y alimentos fermentados (Kurtzman, Fell, \& Boekhout, 2011; Richardson \& Warnock, 2011).

Candida guilliermondii, se encuentra aislada en la piel normal de las personas, en el agua de mar, en el suero de leche, productos fermentados y en especial la cerveza (Rippon, 1988; Pfaller, y otros, 2006).

Candida sphaerica, es una levadura que tiene como hábitat vegetales, productos fermentados como el queso, cereales remojados; también puede estar presente en la piel de humanos y animales; por lo que la presencia de esta puede atribuirse a los ingredientes utilizados, como también al proceso fermentativo por el que cruza el sustrato (Luna, Rufino, Campos, \& Sarubbo, 2012).

Candida utilis se encuentra aislada en flores, pero también puede desarrollarse en alimentos fermentados; lo que sugiere que la presencia de dichos microorganismos se pueden atribuir a la etapa fermentativa que atraviesa (Kurtzman, Fell, \& Boekhout, 2011).

\section{Conclusiones}

La bebida fermentada tradicional "chicha de arroz" en la provincia Bolívar es elaborada artesanalmente y presenta variación en su preparación ya que no existe un control estricto en cuanto a los parámetros de elaboración de la misma. La chicha de arroz es una bebida cuyo perfil microbiológico, en este estudio, podría atribuirse a las características y la calidad de sus ingredientes además de su forma de elaboración ya que los tipos de enterobacterias y mohos encontrados en la misma según datos bibliográficos son propios de los ingredientes utilizados, y la forma de preparación de la bebida.

En cuanto a los valores de los recuentos de enterobacterias, bacterias lácticas mohos y levaduras presentes en las chichas son similares entre productores; las poblaciones microbianas presentes 
en la "chicha de arroz" cambiaron según la etapa fermentativa en la que esta se encontraba. También se ha determinado que en la bebida tradicional "chicha de arroz" se encuentran cepas representativas de enterobacterias, mohos, bacterias ácido lácticas y levaduras, lo cual indica la posibilidad de que estas sean obtenidas por medio de esta bebida como fuente natural de aislamiento. El aislamiento de cepas con propiedades metabólicas adecuadas para la formulación de cultivos iniciadores en un proceso de fermentación controlado, se convierten en una alternativa viable para el desarrollo de un producto inocuo, de alta calidad que pueda cumplir con los estándares más exigentes.

\subsection{Perspectivas futuras}

Es necesario caracterizar molecularmente las cepas. Se recomienda indagar y estudiar otro tipo de bebidas fermentadas tradicionales de nuestro país ya que, al identificar la diversidad microbiana presente en estas, se podría en un futuro, industrializar las cepas que presenten una importante capacidad fermentativa; por lo que es recomendable preservar como potenciales inóculos las cepas nativas encontradas en las bebidas tradicionales del Ecuador para estudios posteriores, y así también establecer rangos comparativos para poder comparar la calidad microbiológica de las bebidas fermentadas tradicionales debido a que son de consumo masivo en países latinos.

\section{Bibliografía}

Alimentos, C. I. (2000). Microorganismos de los alimentos. Zaragoza: Acribia.

Arroyo, A., Bencomo, M., \& Bianco, H. (2011). Perfil microbiológico de la chicha de venta ambulante en Abrquisimeto. Universidad Centrooccidental Lisandro Alvarado.

Bagley, S. (1985). Habitat association of Klebsiella species.

Bayas, A., Jines, D., Salazar, G., \& Del Pozo, F. (sf). Modelización del efecto del tiempo en la densidad y grados brix de la chicha elaborada a partir de cebada germinada enriquecida con maiz amarillo (Zea mays). Ambato: Universidad Técnica de Ambato.

Cartagena, D., Centellas, K., Torrico, N., Saavedra, E., \& Sejas, M. (2009). Contaminación enterobacteriana del guarapo de una fábria de Cochabamba, en fermentacion normal y fermentación flemosa. Revista Ciencia Ciencia Médica SCIELO.

Cervantes , M., \& Pedroza, A. (2007). El pulque: características microbiológicas y contenido alcohólico mediante espectroscopia. Instituto Politécnico Nacional Ticoman.

Decheco , A. (2009). Análisis Microbiológico de Bebidas. Perú: Universidad Nacional Federico Lorca.

Dworkin, M., Falkow, S., Rosenberg, E., Schleifer, K., \& Stackebrandt, E. (2006). The Prokaryotes. Springer.

Ecuador, M. d. (2012). Ecuador culinario - saberes y sabores. Quito. 
Estela, W., Richtera, M., Melzoch, K., Hatta, B., Quillama, E., Ludeña, Z., . . Chaquilla, G. (2011). Actividad Fermentativa de Hanseniaspora uvarum y su importancia en la producción de bebidas fermentadas. Revista de la Sociedad Venezolana de Microbiología, V35. N1.

Fula, A. (2010). Desarrollo de una bebida fermentada con adición de cocción de maiz. Colombia: Universidad Nacional de Colombia.

Gamazo, C., López, I., \& Díaz, R. (2009). Manual Práctico de Microbiología. Barcelona - España: Elsevier Masson.

García, C., Arrázola, G., \& Durango, A. (2010). Producción de ácido láctico por vía tecnológica. Universidad de Córdova.

Gassem, M. (2002). A microbiological study of Sobia: a fermented beverage in the Western province of Saudi Arabia. World Journal of Microbiology \& Biotecnology.

Giles, M., Hernández, G., Córdova, M., López, A., Gosset, G., Bolívar, F., \& Escalante, A. (2001). Estudio de la diversidad bacteriana durante la fermentación del pulque, una aproximación polifásica. México: UNAM.

Grimont, F., \& Grimont, P. (2006). The genus Enterobacter; prokariotes.

Holt , J., Krieg, N., Sneath, P., Staley, J., \& Williams, S. (1994). Bergey's Manual of Determinative Bacteriology. Lippincott, Williams \& Wilkins.

INEC. (2009). Sistema agroalimentario del Arroz. Ecuador.

Jerpersen, N. (2002). Ocurrence and taxonomic characteristics of strains of Saccharomyces cerevisiae predominant in African indigenous fermented foods and beverages. Federation of European Microbiological societies, Dinamarca.

Jiménez, R., González, N., Magaña, A., \& Corona, A. (2010). Evaluación microbiológica sensorial de fermentados de pozol blanco con cacao (Theobroma cacao) y coco (Cocos nucifera). Universidad Juárez Autónoma de Tabascto.

Kurtzman, C., Fell, J., \& Boekhout, T. (2011). The Yeast: a taxonomy study. San Diego - USA: Elsevier.

Libkind, D., Gadanho, M., \& Broock, M. (2007). Studies on the hetrogeneity of the caraotenogenic Rhodotula mucilaginosa from Patagonia. Argentina: Universidad Nacional de Comahue.

López, W., Ramírez , M., Mambuscay, L., \& Osorio, E. (2010). Diversidad de levaduras asociadas a chichas tradicionales de Colombia. Revista Colombiana de Biotecnología, 176 - 186.

Luna, J., Rufino, R., Campos, G., \& Sarubbo, L. (2012). Properties of the biosurfactant produced by Candida sphaerica cultivated in low-cost substrates. Catholic university of Pernambuco, Brasil: Center of Science and Technology.

Noriha, A., Hamidun, B., \& Indu, B. (2011). Erwinia mallotivora sp. a new pathogen of papaya (Carica papaya) in Peninsular Malysia. Malaysian Agricultural Research and Development institute.

Pfaller, M., Diekema, J., Mendez, M., Kibbler, K., Erzsebet, P., Chang, S., . . The global antifungal surveillance group. (2006). Candida guilliermondii, an opportunistic fungal pathogen with 
decreased susceptibility to fluconazole. Iowa - USA: Department of pathology, University of lowa.

Proaño, V. (2009). Chicha de arroz: una bebida muy refrescante.

Ramírez, J., Rosas, P., Velázquez, M., Ulloa, J., \& Arce, F. (2011). Bacterias lácticas: Importancia en alimentos y sus efectos en la salud. Universidad Autónoma de Nayarit.

Reiss, E., Shadomy, J., \& Lyon, M. (2012). Fundamental medical micology. New Jersey - USA: Willey-Blackwell.

Richardson, M., \& Warnock, D. (2011). Fungal infection: diagnosis and management. Washington DC - USA: Wiley- Blackwell.

Rippon, J. (1988). Medical micology. Philadelphia - USA: W.B. Saunders CO.

Rosas, A. (2012). Análisis de chicha de jora como elemento de identidad gastronómica y cultural de la ciudad de Cuenca. Cuenca: Universidad de Cuenca.

Samson , R., Hoekstra, E., Frisvad, J., \& Filtenborg, O. (1995). Introduction to Food-borne Fungi. Holanda.

Sanchez, M., López, C., Flores, M., Jofre, A., Aguirre, J., Morales, E., \& Reyes, R. (2010). Estudio preliminar del Axocot, bebida tradicional fermentada, bajo una perspectiva transdisciplinaria. UNAM.

Sanders, M., Morelli, L., \& Tompkins, T. (2003). Sporeformers as human probiotics: Bacillus, Sporolactobacillus, and Brevibacillus. Comprehensive reviews in food science and food safety.

Stainer, R., Ingraham, J., Wheelis, M., \& Painter, P. (2005). Microbiología. Barcelona, España: Reverté S.A. 